\title{
IT \& Mobile Tower Infrastructure Industry Collaboration - Leap towards Green, Smart \& Sustainable Future
}

\author{
Vikas Dua $^{1}$ \\ ${ }^{1}$ Country Delivery Leader, Service Assurance \& Asset Manager, IBM India, New Delhi, India \\ Correspondence: Vikas Dua, 176 HEWO Apartments, Sectore 15 - II, Gurgaon 122001, Haryana, India. Tel: \\ 91-98-9922-8032. E-mail: vikasdua.1972@gmail.com, vikasdua@in.ibm.com
}

Received: April 26, 2012

Accepted: November 9, 2012 Online Published: November 21, 2012

doi:10.5539/mas.v6n12p37

URL: http://dx.doi.org/10.5539/mas.v6n12p37

\begin{abstract}
Purpose

Suggesting, how IT and Mobile Tower Infrastructure Industry in India can collaborate to drive the benefits of implementing "Smart" solutions in the three imperatives (enabling new business models; differentiating the customer experience; and improving operating efficiencies) and contribute to sustainable development through analysis of various insightful points, both quantitative and qualitative.
\end{abstract}

Design/Methodology/Approach

This report utilizes a variety of research sources in preparing this Report. Key component of the Research analysis includes secondary research and where applicable, all secondary research sources are appropriately cited within this report. These research sources, combined with industry data and expertise, are synthesized into the qualitative and quantitative analysis, as presented in this report.

\section{Findings}

IT Providers can enable the Telecom Tower Industry with "Smart" solutions that can help the companies improve \& be sustainable on all the essential ROI Drivers - Revenue, OPEX, CAPEX and Partner management especially in the area of Energy Management and contribute to sustainable development. The optimization of costs can be further supported by transition to renewable energy sources.

\section{Research Limitations/Implications}

The research is primarily based on secondary data combined with Industry data and expertise. Though the finding / recommendation of the research apply to the entire Industry but the impact on individual companies within the industry can vary, basis the maturity in data $\&$ business processes.

\section{Practical Implications}

Smarter solutions can be implemented by the companies, basis their individual problem statements, varying from addressing a particular process to new types of business models. We need to ensure that the regulations, policies and other stakeholders encourage \& surge ahead towards the larger common goal such that thrust for sustainable development serves as one of the key item.

\section{Social Implications}

Smart Solutions can support Industry to reduce the Carbon Footprint, which stands at 5.63 Million Tonnes exclusively from the burning of Diesel in Tower Infrastructure space in India. This can help Industry to contribute significantly towards "Greener" Environment.

Keywords: smart, IT, tower, mobile, green, carbon, sustainable, solutions

\section{Introduction}

Developing nations represent some of the world's fastest growing mobile communications markets. Mobile communications technology is a significant contributor to nation's economic development, providing millions of individuals with opportunities to participate in the free market, grow their business, more easy access to facilities such as healthcare, and so on. 
The phenomenal growth in mobile subscribers in India over the last few years has created huge opportunities for the Telecom Industry. During the last 5 years, with new players coming in, the intensity of competition in the Telecom industry has increased. The market share of the telcos, as per the analysis by ICRA, reflects the fragmented nature of the industry, which features as many as 15 players (Figure 1). This has led to a steep decline in the Average Revenue per User (ARPU). Figure 2 brings out the pressure on ARPUs for GSM and CDMA operators. As per Telecom Regulatory Authority of India (TRAI) report on Telecom Services Performance Indicators of Nov'11, ARPU figures stand as - INR 98 (USD 1.96) for GSM and Rs. 64 (USD 1.28) for CDMA. This has been exerting pressure on the profitability of the telcos.

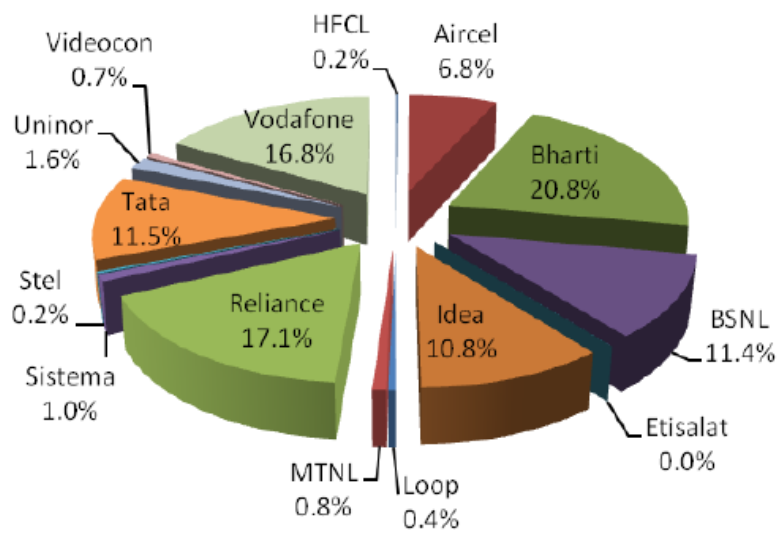

Figure 1. The fragmented nature of the industry

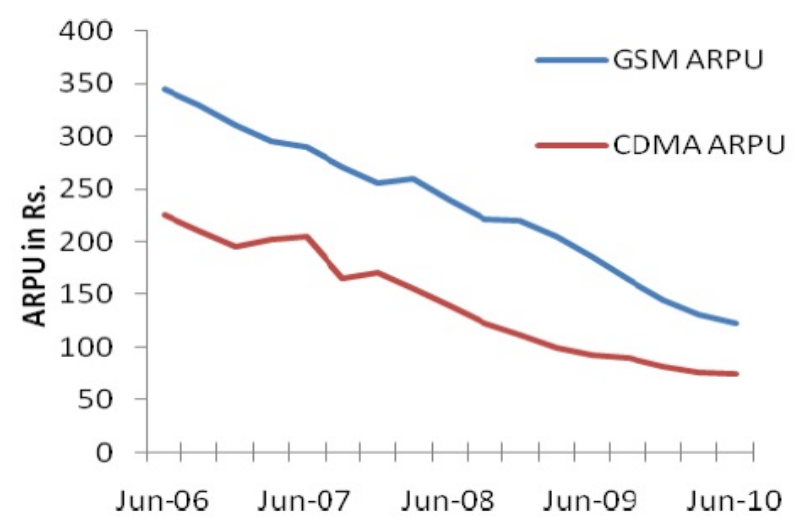

Figure 2. The pressure on ARPUs for GSM and CDMA operators

The intensity of competition has forced the telecom operators to look for cost-cutting measures. One such measure has been the hive-off of telecom tower related operations into separate companies to allow for greater operating efficiencies and tower sharing.

Globally, tower sharing has emerged as key growth driver for the telecom industry, providing benefits as cost reduction, faster rollout, and improvement in asset turnover. However, the ownership and management of telecom towers have largely been in the hands of telcos. ICRA study (Indian Telecom Tower Industry: Consolidation Round the Corner, Feb 2011) states telecom tower industry has gained prominence as an independent industry primarily in two countries, India and USA (Figure 3). 


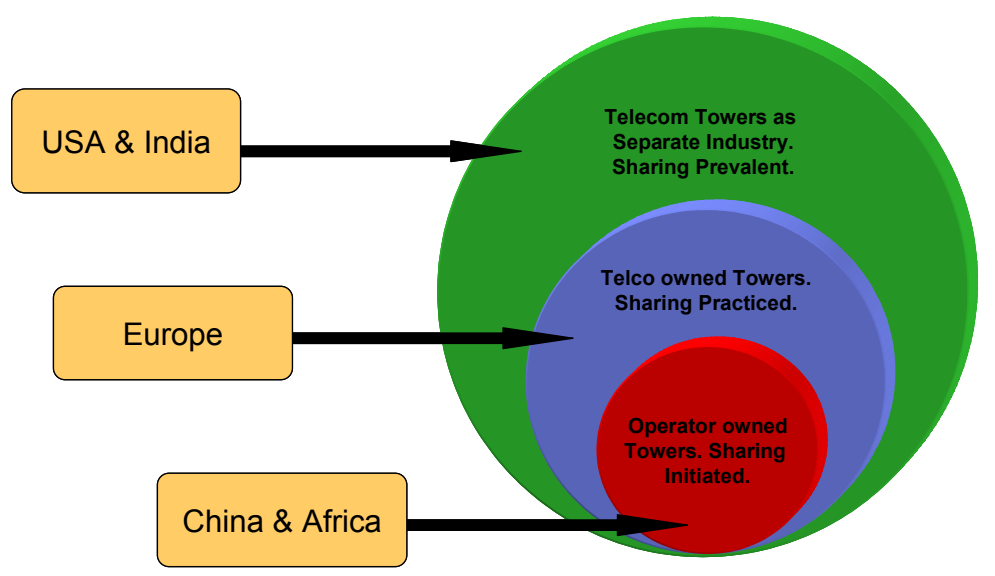

Figure 3. Distribution of telecom tower industry - international scenario

As per the data available in www.tele.net.in, since 2006, the Indian tower industry has almost quadrupled in size with the number of towers growing from 85,000 to around 400,000 . This high growth rate may be attributed to tower build-outs by the industry in anticipation of the strong demand for towers. However, over the past year, tower companies have scaled down and have now become more disciplined in tower rollout plans in order to avert an oversupply situation

This growth has come at a price, and that is "the environmental impact". TRAI report on Green Telecommunications of Feb 2011 suggests the telecom towers and base transceiver station, consumes up to $86 \%$ of energy -- of which the tower site uses $65 \%$ while the core network uses $21 \%$. India consumes two billion litres of diesel annually. This is because $70 \%$ of these towers are in rural areas, with irregular grid power supply. While 30\%-40\% per cent of the power needs are met by grid electricity, the remaining $60 \%-70 \%$ per cent comes from Diesel Generators (DGs). The total $\mathrm{CO}_{2}$ emission is around 5 million tonnes due to diesel consumption and around 8 million tonnes due to power grids per annum.

With the Industry facing numerous challenges, there is a potential to carve out a sustainable approach, both near and long term, through the strategic role play of IT and by effectively managing Telecom Towers to contribute towards improving its profitability and at the same time be front runner by positively contributing towards "Greener Environment".

\section{Literature Review}

Telecom sector in India has emerged as one of the biggest success stories of corporate India. As the wireless telecom grew at a breathtaking speed in India, telecom tower industry surfaced as a thriving business model riding the wave of telecom success.

Tower industry witnessed growth rate of beyond 30\% for the five years, post 2006.2011 witnessed some key developments in the tower infrastructure arena. These included a shift in focus from Greenfield tower rollouts to increasing tenancies, a move towards consolidation, increasing uptake of renewable energy solutions, and the upgradation of a large part of tower infrastructure to $3 \mathrm{G}$ Technology.

Power and energy consumption for telecom network operations is by far the most significant contributor of carbon emissions in the telecom industry. However large parts of the country are power deficient and with increasing coverage of mobile services in off grid areas, network operations will increasingly have to rely on alternative sources of energy until the rural electrification process is complete.

TRAI consultation paper calculates that the energy costs amount to nearly $25 \%$ of the total network operating costs. Given that the international supply and demand gap is resulting in increase in the price of diesel which would result in increase in the operational cost associated with managing networks, this may affect the profitability of operators, some of whom are already seeing profit erosion because of competition. According to an estimate, telecom companies are currently spending INR 3 Billion (USD 60 Million) a month for running DGs in remote areas where there is irregular grid power supply.

With the double whammy of increasing energy consumption and rising cost of fossil fuel, it is important that the focus shifts to energy efficient technologies and alternate sources of energy. 
TRAI has recommended for all the operators that at least $50 \%$ of all rural towers and $20 \%$ of all urban towers are to be powered by hybrid power by 2015 . The draft National Telecom Policy 2011 recognizes the need for the creation of large-scale and quality telecom infrastructure as a key to rapid economic and social development of the country. The other significant regulatory development with respect to tower companies would be getting the status of essential infrastructure.

In the current scenario, Telecom Tower Industry is of the view that there is a need for a paradigm shift in the business model, with the emergence of energy companies as a new link in the telecom value chain. Tower operators are of the view that a new business model, renewable energy management companies or energy management companies should be set up with government support. Infrastructure providers and the Tower and Infrastructure Provider Association have suggested the promotion of such a model to Department of Telecommunications (DoT).

\section{Research Methodology}

We have utilized a variety of research sources in preparing this Research Report. The key component of the Research's analysis includes secondary research and where applicable, all secondary research sources are appropriately cited within this report.

These research sources, combined with industry data and expertise, are synthesized into the qualitative and quantitative analysis presented in this report. Great care is taken in making sure that all analysis is well-supported by facts, but where the facts are unknown and assumptions must be made, we have documented assumptions and are prepared to explain their methodology, within the body of the report.

This Research paper is an independent view with a goal to present an objective, unbiased view of market opportunities within its coverage areas. There is no beholden to any special interests and unfettered by technology hype, political agendas, or emotional factors that are inherent in the markets.

\section{Telecom Tower Industry in India - A Glance}

Driven by the exponential growth in the wireless subscriber base ( 850 million+), network expansion and the launch of $3 \mathrm{G}$ and broadband wireless access services, the wireless segment paved the way for the emergence of the independent tower industry in 2007.

The compelling opportunity in the tower leasing space prompted major operators, including Bharti Airtel, Reliance Communications (RCOM) and Tata Teleservices Limited to hive off their tower assets into separate subsidiaries. Capitalizing on the strong demand for towers, several stand-alone tower companies including GTL Infrastructure Limited (GIL), Tower Vision and Viom Networks (formerly WTTIL-QTIL) also entered the market.

Each tower depending on whether it is GBT (Ground Based Tower) or RTT (Roof Top Tower) requires a high capital investment ranging from INR $1.5-2.5$ million (USD $0.03-0.05$ million). As per the data available in www.tele.net.in, the monthly rentals charged by tower companies are approximately to the tune of INR 25,000 32,000 (USD 500 - 640) for GBT and INR 18,000 - 21,000 (USD 360 - 420) for RTT per operator. The operating expenditure, as prevalent in the industry, like rent, fuel and energy charges is shared by the tenants on a monthly basis.

Passive infrastructure sharing is a key trend that the tower industry has witnessed over the past four years. This concept started gaining traction in the Indian wireless industry, driven mainly by the initiatives of the government that launched Project MOST (mobile operators' shared towers) in 2006.

The business model of Tower Industry provides for a high incremental profit when the tenancy ratio is improved. As per the data available in www.tele.net.in, most of the key players stood at upwards of 1.6x levels in Tenancies. With the slowdown in rollouts, tenancy levels below the optimal $2.5 x$ levels and a situation of overcapacity in urban areas, tower companies had a tough year. GTL Infrastructure, for instance, faced some trouble in the second half of 2011, with a total debt of INR 100 billion (USD 2 billion) on its books. With a tenancy level of $2.4 \mathrm{x}$, the highest in the industry, Viom Networks has ventured into the international market as tower companies in India continued to be burdened with huge debt and falling revenues

While operator-owned tower companies currently dominating the market, true independents are also holding their own and have significantly enhanced their tower portfolios over the past 2-3 years by way of mergers and acquisitions (M\&As) and consolidation. Some of the bigger M\&A deals in the sector include GIL's takeover of Aircel Cellular's tower business and the merger of WTTIL with QTIL. 


\subsection{Carbon Footprint}

As per the TRAI report on Green Telecommunication of April 2011, India has 12\% power shortage with less than $52.5 \%$ of rural households have access to electricity. In 2009, the overall electrification rate in India was $66.3 \%$. Due to the precarious power situation about $40 \%$ of the telecom towers have Electricity Board (EB) power availability of less than 12 hours. Table 1 shows availability of power in different types of cell site locations.

Table 1. Availability of power in different types of cell site locations

\begin{tabular}{lll}
\hline Cell Sites & EB Availability & Description \\
\hline $10 \%$ & $>20 \mathrm{hrs}$ & $\begin{array}{l}\text { Mainly metro cities of Mumbai, Kolkota, Chennai, some } \\
\text { cities of Gujarat, State of Chattisgarh, some cities of Punjab } \\
\text { Covers most other major cities and towns in the rest of the } \\
\text { country }\end{array}$ \\
$20 \%$ & $16-20 \mathrm{hrs}$ & $\begin{array}{l}\text { All semi-urban and small urban towns in all states } \\
\text { Mostly rural areas }\end{array}$ \\
$25 \%$ & $8-12 \mathrm{hrs}$ & $\begin{array}{l}\text { Mostly parts of Bihar and some towns of Assam, NE states, } \\
\text { UP and J\&K }\end{array}$ \\
\hline
\end{tabular}

Source: Intelligent Energy Limited.

Deficient grid power makes it imperative to use non-grid sources, the most common being DGs. Basis the above Availability chart, Average Run Hours for DG falls in the range of 6 - 8 Hrs per cell site. The calculation, as part of this research, on total Diesel consumed and $\mathrm{CO}_{2}$ emission is enclosed below in Table 2 with outlined assumptions, as per Industry standards.

Table 2. The calculation on total Diesel consumed and $\mathrm{CO}_{2}$ emission

\begin{tabular}{|c|c|c|c|c|c|c|c|}
\hline \multirow{7}{*}{$\begin{array}{l}\text { Tower } \\
\text { Sites }\end{array}$} & Average & Average & Average & Average & Average & & \multirow{2}{*}{$\mathrm{CO}_{2}$} \\
\hline & Diesel & Diesel & OPEX & OPEX & OPEX & $\mathrm{CO}_{2}$ & \\
\hline & Consumption & Consump & Cost for & Cost for & Cost for & Emission & \multirow{3}{*}{$\begin{array}{l}\text { Emission } \\
\text { per annum }\end{array}$} \\
\hline & per Tower per & tion per & Diesel & Diesel per & Diesel per & per Day & \\
\hline & Day@7Hrs & Day & per Day & Annum & Annum & & \\
\hline & & (Million & (Million & (Billion & (Billion & (Metric & (Million \\
\hline & (Litres) & Litres) & INR) & INR) & USD) & Tonne) & Tonne) \\
\hline 400000 & 14 & 5.60 & 224.00 & 81.82 & 1.64 & 15008.00 & 5.48 \\
\hline \multicolumn{8}{|c|}{ * Assuming DGs Power Rating (10 KVA-20 KVA) consumes around 2 Litres/Hour; } \\
\hline \multicolumn{8}{|c|}{ * 1 Litre of Diesel emits $2.68 \mathrm{Kg}$ of $\mathrm{CO}_{2}$; } \\
\hline \multicolumn{8}{|c|}{ * Average Diesel Consumption per Tower per Day 7 Hrs; } \\
\hline 1Litre@ & s. 40; & & & & & & \\
\hline
\end{tabular}

The total $\mathrm{CO}_{2}$ emission is around 5.48 Million Tonnes per annum due to diesel consumption. The higher carbon footprint reflects the diesel required to augment the poor supplies of power from the grid in India. We should take into account that the above is only a direct impact due to burning of diesel through DGs. The impact due to various other factors like Grid Power \& Cooling Unit etc is over \& above these figures.

Further to the above, in case, we also consider the indirect impact due to regular Operation \& Maintenance (O \& M) activities like Site Engineers visiting the Tower Sites on a vehicle (Table 3), the impact on environment has 
far reaching consequences. It has been assumed that travelling a distance of 10 to $12 \mathrm{Km}$ by vehicle, add $1 \mathrm{Kg}$ of $\mathrm{CO}_{2}$ to Carbon Footprint in the below calculation.

Table 3. The indirect impact due to regular Operation \& Maintenance (O \& M) activities

\begin{tabular}{lr}
\hline & \multicolumn{1}{c}{ Initial State } \\
\hline Critical incidents per site per day & 1 \\
Percentage sites to be visited daily by field staff & $100 \%$ \\
Trips/day for 400000 sites & 400000 \\
Carbon Footprint per day (metric tonnes of $\mathrm{CO}_{2}$ ) & 400 \\
Carbon Footprint per annum (metric tonnes of $\mathrm{CO}_{2}$ ) & 146100 \\
Carbon Footprint per annum (Million tonnes of $\mathrm{CO}_{2}$ ) & 0.15 \\
\hline
\end{tabular}

\section{Assumptions}

1) Critical Alarm at site requires site visit by technicians. Assumption is 1 Critical incident happen per site per day.

2) Critical incidents are: DG FAILED TO START, FIRE AND SMOKE, HIGH TEMPERATURE, LOW BATTERY VOLTAGE, SITE DOWN.

3) A single technician is responsible for upto 10 sites within a radius of 5-7 kilometres. Average trip is 10-12 Kms.

4) Travel of 10-12 Kms on a vehicle results in $1 \mathrm{Kg}$ of CO2 emission.

5) The above does not take into the account any extra trips by Technicians for carrying our Preventive maintenance.

The total $\mathrm{CO}_{2}$ emission (as part of this research) including the above, is around 5.63 Million Tonnes with direct Average Cost on Fuel alone as USD 1.64 Billion.

TRAI report on Green Telecom of April 2011 suggests, the mobile subscriber base in India is expected to reach 1 billion mark shortly. This would imply an additional requirement of around 250,000 more mobile towers with a projected total annual emission of nearly $30 \mathrm{mt}$ of $\mathrm{CO} 2$. Given the huge carbon foot print of the Industry, every steps taken to help reduce Carbon, would benefit our environment.

TRAI has recommended that service providers should aim at Carbon emission reduction targets for the mobile network at $8 \%$ by the year $2012-2013,12 \%$ by the year $2014-2015,17 \%$ by the year $2016-2017$ and $25 \%$ by the year 2018-2019.

\section{Key Challenges Facing the Tower Industry}

\subsection{Business}

a. High costs of telecom infrastructure: High initial capital investment is one of the major challenges faced by the industry.

b. Energy Costs: Account for up to $60 \%$ of the OPEX and even more in rural areas. TRAI report on Green Telecom (April 2011) suggests, Indus Towers alone is the third largest consumer of diesel in India after the army and the railways.

c. Tower Valuation: Tower valuations have been on a decline over the past three years and are currently in the range of Rs 4.8 million to Rs 5.2 million per tower, according to industry experts.

d. Rentals: With operators facing margin pressures, the rentals have been on a decline. They reduced by around $20 \%$ over the past some time.

e. Operating Cash Flow: At operational level issues around pilferage / theft of diesel and labour continue to exert pressure on the balance sheet of Tower companies. As per the Industry sources, the other element hurting the cash flow is varied and host of taxes on the premises and equipment. 
f. Long term Strategic improvements and Operational Efficiency gets hindered due to lack of Operational visibility, Data Availability around Assets or Site state and Analytics. The maturity of Tower companies is varied in this aspect.

g. Debt: As per the Industry sources, the overall debt of the Tower sector is estimated to be around INR 1,000 Billion (USD 20 Billion). The debt accumulated after the 3G spectrum payouts queered the pitch further.

h. Active infrastructure sharing (network sharing): Active infrastructure sharing limited to antenna, feeder cable, node B, Radio Access Network and transmission systems is allowed. However, bottlenecks in the adoption are the lack of points of interface for interconnections and degree of loss of control over the shared equipment. While the Indian tower companies have streamlined the sharing of passive infrastructure, they are yet to fully operationalize the sharing of active infrastructure.

i. Telecom Industry Financial Status: Brief analysis of the quarter wise Net Profit margins of Telcos suggests that the margin percentage are either flat or reducing, thereby creating pressure on the overall Financial position of the Industry.

\subsection{Policies \& Governance}

a. Spectrum sharing: This model has recently surfaced in mature, regulated environments. Spectrum sharing is not permitted in India yet.

b. Red Tape: The operators face challenges in obtaining permission for their sites from regulators and government authorities. There is no uniformity in the taxes levied by the government authorities on these towers and it varies from municipality to municipality even within the state. Approvals take more than 6 months in some cases.

c. Currently tower companies are not subject to license fee or revenue share. TRAI has suggested to the government to impose revenue share on telecom tower companies and internet service providers at $3 \%$ on their annual revenues by $2012-13$ and $6 \%$ by $2015-16$. The Telecom Commission accepted TRAI's proposal, but hiked the revenue share to $8 \%$ for all telecom services, increasing the industry outgo by several hundreds of million annually.

$d$. The outbreak of $2 \mathrm{G}$ scam and related developments has negatively impacted the investments especially foreign in the sector. The companies have been consolidating and providing services like $3 \mathrm{G}$ in areas where they see highest revenue opportunity, such as metro cities.

\subsection{Socio-economic}

a. Carbon Footprint: As calculated in the paper, the carbon foot print through use of Diesel is around 5.63 million tonne.

b. Radiations: There is also the issue that mobile towers have a higher emission of electromagnetic radiation, which is beyond safety levels. An inter-ministerial committee has recommended to DoT that the radiation level norms be brought down by one-tenth, from the current 9.2 watts per sq $\mathrm{mt}$ to less than 1 watt per sq $\mathrm{mt}$.

c. As per the estimates shared in our paper, Telecom Towers contribute to burning around 5.60 Million Litres of Diesel annually at a cost of USD 1.64 billion. Apart from the cost, we are burning a scarce resource in aplenty. Diesel prices in India are heavily subsidized due to political reasons. However, the facts suggest that the impact of the overall subsidy is not reaching the desired audiences.

\section{Key Trends in Telecom Tower Industry}

a. Towards cost optimization of telecom infrastructure: There is an increasing focus on graded methods of CAPEX and/or OPEX savings. Towards this, various business models have evolved in recent years, such as energy audits benchmarking, critical process improvements and field maintenance.

b. Passive infrastructure sharing: Few of the key strategic drivers for passive sharing include: Lower site acquisition times for entrants, Access to locations of strategic importance, Reduced OPEX, Expansion \& Reduce Environmental concerns.

c. Increasing Tenancies: The industry has now shifted from focusing on tower build-out to increasing tenancies. All key players in the industry witnessed a significant increase in tenancies in 2010, with tenancies over 1.6x levels for most players.

d. Light weight Tower Design: The industry is also moving towards enhanced use of high capacity multi-tenancy towers. In order to reduce costs, it is looking at streamlining tower design and making them lightweight and tubular. Tower companies are also looking to downsize older uneconomical towers in a phased manner. 
e. Consolidation: As the industry gets ready to enter its next phase of development, opportunities for organic growth and acquisitions continue to be strong and there is a compelling rationale for consolidation among tower companies. RComm is in discussion with a consortium of private equity firms Blackstone and Carlyle to divest its stake in tower subsidiary, Reliance Infratel. This trend of consolidation in the tower industry is likely to continue.

\section{Smart Solutions - Impact to Industry's Core Business for Green \& Sustainable future}

The industry is, undoubtedly, in a time of tight fiscal constraints which can have a larger impact on the industry's ability to capitalize on growth opportunities and address long term cost savings projects. Regulatory constraints continue to act as inhibitors. Legacy infrastructure, complex global processes and meltdown of financial markets are enormous barrier of change.

Survival means innovative services, radical approaches to cost reduction, new business models and partners. IT can play a big collaborative role with the Industry to implement \& interconnect smart solutions that can help to address some of the "critical" challenges, mentioned in the paper (help reduce costs, enhance the customer experience, and enable new ways of doing business). Smarter solutions can be implemented by starting "small" (e.g., addressing a particular process or business challenge) or by addressing the larger strategic issues (e.g., new types of business models).

The need of the hour for the Industry is implement "Smart Solutions" to ensure that the real time state of the site spread across the nation \& assets are known immediately and process orchestration across IT, Technology and O\&M are effectively mapped. Analytics layer based on the wealth of data can then provide valuable insights to Process Performance, Asset Performance and Energy Analytics. Using that, companies can foray into the next steps of trending to save on various forms of OPEX \& CAPEX cost. Let us to a deep-dive with few specifics that such a smarter solution can unfold:

i. Real time view on Events highlighting the state of the site can help the company to closely monitor control parameters like Uptime (Site Down, BTS Down, DG Fail to Start \& DG Fault etc), Energy Cost (Main Fail, DG ON, DG Failed to Stop \& Manual Mode etc) and Safety (Fire \& Smoke). The above tightly coupled with end to end integration of Assets, Process Orchestration \& Intelligence provide opportunities to help monitor, control \& eventually improve upon Control parameters around Uptime, Energy Cost \& Safety. Individual Event / Alarm status \& its frequency can unfold various opportunities for reduced Fuel usage like:

a. Low Battery Voltage is a big contributor in a normal operating environment in a Tower site. In case of power outages, batteries are the "last line of defense" before DG needs to be started, so poor battery condition will lead to higher diesel consumption.

b. Analysis on Events like DG Fail to Stop \& Manual Mode can help to unfold immediate "saving" opportunities \& directly contribute towards reducing Carbon Footprint. Any run hours being attributed towards DG Fail to Stop, while EB power is $\mathrm{ON}$ is one of the low lying fruit that can be immediately en-cashed by the companies.

c. Analysis like run hours of EB, DG and Battery Bank (BB) for a day (Table 4) can easily help companies to identify the sites (or group of sites), which consume more than 24 hours. This group of sites can be the first one to be targeted for improvement.

Table 4. Analysis of run hours

\begin{tabular}{|c|c|c|c|c|c|c|c|}
\hline CIRCLE & & $\begin{array}{c}\text { Average DG } \\
\text { run hrs }\end{array}$ & $\begin{array}{c}\text { Average EB } \\
\text { run hrs }\end{array}$ & $\begin{array}{c}\text { Average } \\
\text { BB run hrs }\end{array}$ & $\begin{array}{c}\mathrm{EB}+\mathrm{DG}+\mathrm{BB} \\
\text { run hrs } \\
\end{array}$ & Status & $\begin{array}{c}\% \mathrm{Bad} \\
\text { Sites } \\
\end{array}$ \\
\hline \multirow[t]{4}{*}{ Circle A } & & & & & & & $33.33 \%$ \\
\hline & Site A & 1.3 & 17.25 & 5.45 & 24 & Good & \\
\hline & Site B & 8.11 & 12.2 & 4.87 & 25.18 & $\mathrm{Bad}$ & \\
\hline & Site C & 5.62 & 1067 & 7.71 & 24 & Good & \\
\hline \multirow[t]{3}{*}{ Circle B } & & & & & & & $100.00 \%$ \\
\hline & Site D & 2.3 & 17 & 6.4 & 25.7 & $\mathrm{Bad}$ & \\
\hline & Site E & 7 & 14 & 5 & 26 & $\mathrm{Bad}$ & \\
\hline
\end{tabular}


ii. Typically, most of the sites in a given region are subject to similar environmental conditions ( $\&$ may be, even similar power situations); hence the ratio ( $r$ ) of EB+DG consumption of each site relative to average across all the sites in the region should, ideally, be close to 1 for most of the sites. Typical sample ratios are shown in Table 5 below. While some of the cases may be legitimate (due to different loading), but the sites with exceptionally high number are the immediate opportunity areas for the company to target optimization potential. One of the common reasons for the difference could be oversized generators running at low loading, and hence yielding poor fuel efficiency.

Table 5. Typical sample ratios

\begin{tabular}{ccc}
\hline Ratio $(\mathrm{r})$ & \% of sites $(\mathrm{x})$ & Remarks \\
\hline Below- 0.5 & $12 \%$ & Low, Further analysis should be done to understand the root \\
$0.6-1.7$ & $40 \%$ & cause \\
& & Average. Further, analysis should be done to understand the root \\
$1.8-3.0$ & $30 \%$ & Problem. These should be immediately targeted for a detailed \\
$3.0-4.5$ & $10 \%$ & Root Cause \& appropriate loop back for correction. \\
4.5 -above & $8 \%$ &
\end{tabular}

iii. Analysis on Energy consumption pattern for the site, over a period of time, can help to identify the cases around "pilferage" / "theft". The "well-behaved" sites on the left (Figure 4) exhibit a relatively uniform energy consumption pattern, whereas the sites on the right show periods of energy consumption much higher than normal. Such analysis gives companies an opportunity to audit and rectify the operations at such sites.
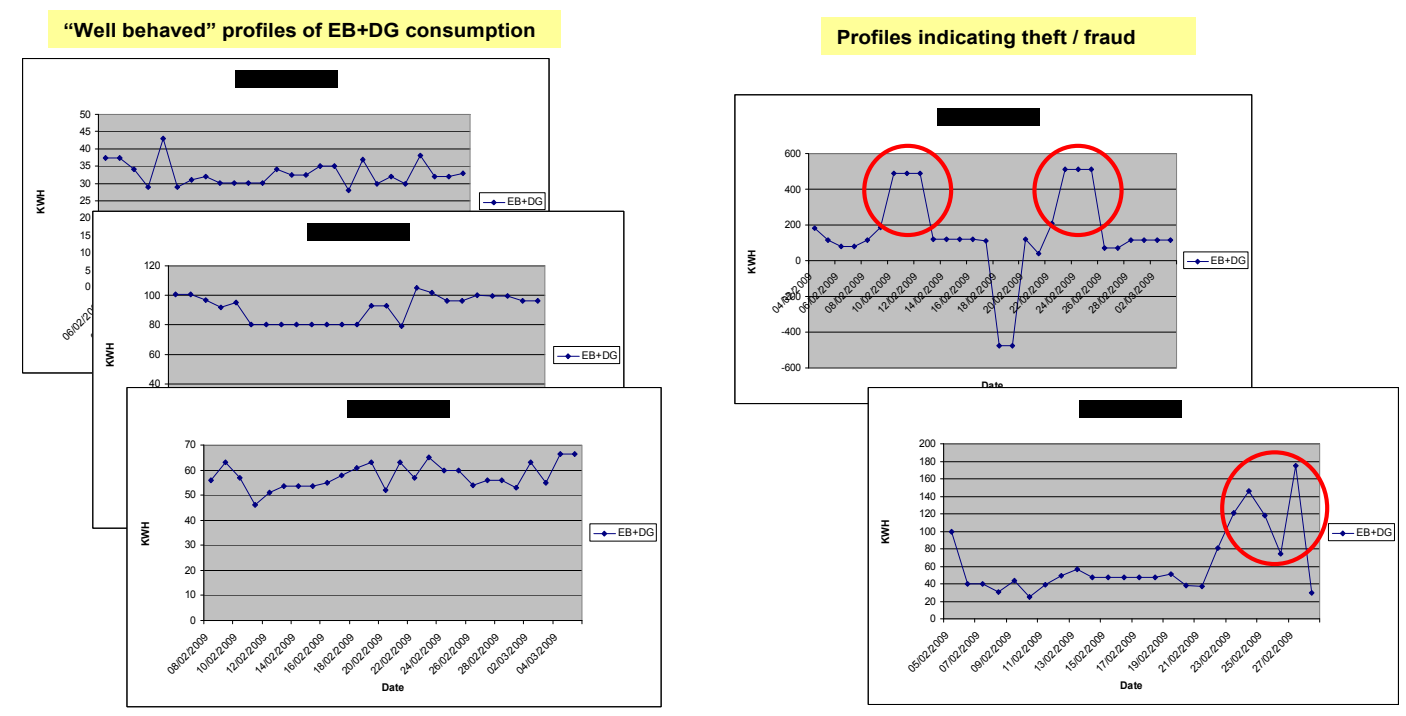

Figure 4. Energy consumption pattern

iv. Generally, Fuel efficiency of DGs will be a function of parameters like vendor, environmental characteristics \& preventive maintenance schedules etc. The premise is an "optimal" or "best practice" site configuration leads to the optimal fuel efficiency. Once such a configuration is identified, it can be replicated across the country (or at least in the region) to achieve better DG performance across the board.

The opportunities thus unfolded, can be direct contributors to Reduced OPEX \& CAPEX requirements, with reduced Carbon Footprint and will act as enablers to devise sustainable approach.

v. In case, we also account the indirect costs $\&$ emissions saved by orchestrating end to end processes over the IT Automation layer: 
There would be fewer trips required by Technicians as now they receive the alerts over their phone, automatically. Table 6 below highlights the reduced Carbon Footprint, basis the assumed improvements. (30\% improvement translate to $33.33 \%$ decrease in Carbon Footprint) This also translates to reduce OPEX for some companies, depending upon their business model.

Table 6. The reduced carbon footprint

\begin{tabular}{lrrr}
\hline & Initial & & \\
& State & 1st Year & Ilnd Year \\
\hline Critical incident per site per day & 1 & 0.70 & 0.40 \\
Percentage sites to be visited daily by field staff & $100 \%$ & $70 \%$ & $40 \%$ \\
Trips/day for 370000 sites & 400000 & 280000 & 160000 \\
Carbon Footprint per day (metric tonnes of $\mathrm{CO}_{2}$ ) & 400 & 280 & 160 \\
Carbon Footprint per annum (metric tonnes of $\mathrm{CO}_{2}$ ) & 146100 & 8400 & 4800 \\
Carbon Footpriont per annum $\quad\left(\right.$ million toones of $\left.\mathrm{CO}_{2}\right)$ & 0.15 & 0.10 & 0.06 \\
\hline
\end{tabular}

\section{Assumptions}

1) Critical Alarm at site requires site visit by technicians. Assumption 1 Critical incident happen per site per da.

2) Critical incidents are DG FAILED TO START, FIRE AND SMOKE, HIGH TEMPERATURE, LOW BATTERY VOLTAGE, SITE DOWN.

3) A single technician is responsible for upto 10 sites within a radius of 5-7 kilometres. Average trip is 10-12 Kms.

4) Travel of 10-12 Kms on a vehicle results in $1 \mathrm{Kg}$ of $\mathrm{CO}_{2}$ emission.

5) The above does not take into the account any extra trips by Technicians for carrying out Preventive maintenance.

6) It has been assumed that Year 1 of implementation would withness a 30\% improvement and in Year 2, critical incidents/site day/reduce to 0.4 .

vi. Real time Site \& Asset Monitoring mapped with effective Preventive Maintenance Process can lead to Optimal Asset Performance with improved Efficiency. Improved Asset Performance can be a direct enabler to Improved Site Uptime, which eventually lead to improve Customer Satisfaction.

These can be direct contributors to Incremental Margins (Higher tenancy \& avoiding SLA penalties) \& Reduced CAPEX.

vii. As the data on "Site Down" \& other parameters is available on real time basis, there is no dependence for data on Network Equipment Providers. The companies are well equipped with data to discuss \& resolve the underlying issues with such vendors.

These can be direct contributors to improved Partner Management.

\section{Smart Solutions - Impact on Drivers for Return on Investment (ROI)}

ROI Drivers through the use of such IT Smart solutions can be broadly calculated as:

$\mathrm{ROI}=\mathrm{f}(\mathrm{M}, \mathrm{O}, \mathrm{C}, \mathrm{P})$ where,

$\mathrm{M}->$ "Incremental" Margins and Revenue $=\mathrm{f}($ Tenancy, Site Uptime, Carbon Credits)

$\mathrm{O} \rightarrow$ "Reduced" OPEX $=$ f(Labor, Energy)

C $->$ "Reduced" CAPEX $=\mathrm{f}($ Asset Utilization, Asset Lifetime $)$

P -> "Improved" Partner Management = f(SLA, Performance Management)

\section{Margins and Revenue}

$\checkmark$ Higher Tenancy

- Lower cost of Operation, leading to lower rentals. This can lead to improved Tenancy. 
○ Higher Up time, Better management of SLAs and Accurate Billing.

Benefit $=(\%$ Tenancy Increase X Number of Towers X Rental X Inflation X Period $)$

$\checkmark \quad$ Higher Site Uptime

- Prevent Passive infrastructure related outages

Benefit $=$ (avoided SLA penalties)

$\checkmark \quad$ New Revenue stream through Carbon Credits

- 1 Carbon Credit $=1$ Ton of $\mathrm{CO}_{2}$.

Benefit $=(5$ Euro $*$ / CER X Carbon Credit earned). This suggests that Industry is riding on 27.4 Million Euro market from "direct" consumption of Diesel alone. * It is assumed that the trading price for a CER is 5 Euro.

\section{OPEX (including Energy Management)}

$\checkmark$ Higher number of Towers can be managed per resource as opposed to the Manual mode

○ Shared Resource Pools at circle, cluster and zonal level.

○ "On-Demand" workforce management, which can be enabled by centralized and remote monitoring.

- Real Time visibility of the work load and workforce deployment.

Benefit $=($ Reduction of Manpower $(n)$ X Average Opportunity Cost X Period $)$

$\checkmark$ Reduction in Work Orders and Tickets.

- Enabled by better Preventive maintenance and visibility of Asset State.

Benefit $=($ Removal of OPEX costs for reduced numbers and out of schedule work orders)

$\checkmark$ OPEX saving enabled by Analytics on Operational Data.

- Energy Efficiency Analysis.

○ Fuel Theft / Pilferage Analysis.

○ DG Sizing

Benefit $=(\%$ Reduction of Energy Components (like Fuel) X Average Opportunity Cost X Inflation X Period $)$

CAPEX

$\checkmark \quad$ Improved Asset Efficiency \& Life time

- Driven by support to enable appropriate sizing for the site.

○ Higher DG, Battery \& other Passive Infrastructure components life through improved Preventive Maintenance.

Benefit $=($ Incremental Period X Average Opportunity Cost X Inflation $)$

$\checkmark$ Avoid redundant Asset Procurement

- Enabled by improved Asset Life time and Real time view of the Asset state.

Benefit $=($ Period X Average Opportunity Cost X Inflation $)$

$\checkmark$ Improved Tower Deployment Planning

- By integrating the solution with RF Planning and Optimization, Tower Deployment process can be optimized.

\section{Partner Management}

$\checkmark \quad$ Driven by visibility of state of the site and availability of SLA data.

○ Reduced dependence on Vendors for the data centered on SLAs. Improved Governance.

- Proactive management of issues impacting Customer.

Benefit $=$ (Improved Customer Satisfaction Index, Better Governance of Vendor)

Bharti Infratel has benefitted by implementation of such a smart solution (http://pcquest.ciol.com/content/contentimplementation2011/2011/211070103.asp). 
Before Deployment: Bharti Infratel had difficulty in monitoring Operational and Energy costs of Passive components suh as DG sets, ACs etc; Delay in Asset breakdown restoration / service maintenance; Difficult to track and manage SLAs for clients.

What was deployed?: A centralized monitoring \& intelligent system using product from IBM Tivoli suites and Rule Engine to optimize Passive Infrastructure Utilization across 30,000+ tower locations, with Implementation Partner being IBM.

After Deployment: Saved Rs. 55 million / year (Energy / Operational) by optimizing DG duringf Power failure' Reduced 4.08 million $\mathrm{Kg}$ of $\mathrm{CO}_{2}$ emissions per year' Automated assignment of defined actionable to the field staff increasing the site uptime to $99.7 \%$

\section{Renewable Energy Sources}

To arrest the increasing expenditure on energy by networks, various energy efficient solutions are slowly being adopted by concentrating on alternative sources of energy and innovative methods. Few of them are Photovoltaic $(P V)$ cells, Fuel cells, Wind and solar energy etc. An initiative is reportedly underway by major players like Bharti Infratel, Indus and BSNL etc. in deploying renewable energy sites as pilots.

There is a significant potential in India for generation of power from renewable energy sources like small hydro, biomass and solar energy. Greater reliance on renewable energy sources offers enormous economic, social and environmental benefits.

India is the world's fifth largest producer of wind power after Denmark, Germany, Spain and USA. Indian Wind Energy Association has estimated the 'onshore' potential for utilization of wind energy for electricity generation to the order of $65,000 \mathrm{MW}$. In wind power, India's total installed capacity is planned to double by 2022. In July 2009, India unveiled a \$19 billion plan, Jawaharlal Nehru National Solar Mission, to produce 20,000 MW of solar power by 2020. India's National Solar Mission aims to see solar energy achieve grid parity with the cheapest coal fired capacity by 2030 and establish the country as a global leader in the field. TRAI in its report on Green Telecommunication suggests operator's payback on Investments as depicted in the Table 7 below.

Table 7. Operator's payback on investments

\begin{tabular}{cccc}
\hline & $\begin{array}{c}\text { 3-year payback } \\
\text { period }\end{array}$ & $\begin{array}{c}\text { 4-year payback } \\
\text { period }\end{array}$ & $\begin{array}{c}5 \text {-year payback } \\
\text { period }\end{array}$ \\
\hline $\begin{array}{c}\text { Percentage of off-grid BTS sites viable } \\
\text { for green power }\end{array}$ & $9 \%$ & & \\
Reduction of diesel per year & 1.1 billion litres & 2.5 billion litres & 3.5 billion litres \\
Fuel cost savings per year & USD 1.3 billion & USD 2.9 billion & USD 4.4 billion \\
& & 6.8 million & 10 million \\
$\mathrm{CO}_{2}$ emission reduction per year & 3 million tonnes & tonnes & tonnes \\
\hline
\end{tabular}

Source: GSMA.

The government has committed to subsidies $50 \%$ on solar panels for such projects in the national budget. A solar panel needed to power a tower costs around Rs.28 lakh. TRAI has recommended that in the next five years, at least $50 \%$ of all rural towers and $33 \%$ of the urban towers are to be powered by hybrid power (Renewable Energy Technologies (RET) + Grid power) by 2015, while all rural towers and $50 \%$ of urban towers are to be hybrid powered by 2020 .

However, it would be useful to ensure suitable redundancy in energy sources to mitigate risks from choosing specific sources of energy or technologies. The risks could specifically involve a sharp change in cost of one or more options. These costs could relate to production, storage and distribution of energy for the many activities related to telecommunications. These would evolve over a period of time.

Going by the economies, distribution of Tower sites across different climatic \& local conditions and current business position of Tower companies, it seems a long distance still need to be covered in this direction. Moreover, there would be a learning curve involved in understanding the dynamics in maintenance of such sites. 


\section{Key Recommendations}

a. There is a definitive case of Telecom Tower Industry to enable their IT landscape such that they can drive the benefits of implementing "Smart" solutions in the three imperatives (enabling new business models; differentiating the customer experience; and improving operating efficiencies), which are fundamental to jumpstart change and sustainability.

b. Basis the maturity of the company \& financial position, the transformation plan should be phased out with a view such that low hanging fruits can be quickly realized.

c. Process Transformation across Business \& IT would be the "key" to fully leverage the value of Data and Analytics. This can help to make their decision making more effective.

d. While the changing landscape towards Renewable Energy Sources would be a reality in future, both, IT Providers \& Telecom Industry need to partner with each other today to invest in the R \& D and come up with "innovative" \& low cost technology solutions.

e. There is a need to promote seed investments in companies offering access to newer technologies in Energy Generation and Management. Models should be promoted wherein localized energy solutions on an OPEX model can be tried by the telecom / tower operator - this would encourage localized product / service development and allow operators to choose the most suitable solution for a region, without losing focus on their core activities.

f. Various stakeholders (like Local Administration, State Governments, National Governments, IT Providers, Communication Industry, Telecom Tower Industry, Grid Infrastructure Provider and Energy \& Utilities etc) need to be on board with a common Vision while devising the Universal Approach on important areas like Renewable Energy Sources \& Carbon Credit Policy etc. They need to be completely aligned with overall objectives.

- The relevant stakeholders need to discuss and close on the carbon credit policy for telecom sector, which can then be enforced and monitored for targeted results.

- Given the scale of telecom operations in the country and the relatively poor quality of infrastructure like power in most areas, more incentives may be required to reduce the adverse impact of certain telecom functions and activities.

- Policies should be such that they promote the use of alternative energy sources.

- Approval process \& Tax structure should be streamlined.

g. To improve the penetration of Green Energy solution, Standards need to be formed by Government in terms of defining the total energy used/Carbon emission for every type of sites. Strict enforcement of these regulations can bring in substantial improvement in Carbon emission.

h. Governance Organization \& Structures, among various stakeholders, would be one of the key in managing the results and take corrective course, as required. The long-term success of the "Smart" Telecom program will rely on its adaptability to the changing demands of business, social and economic levers.

\section{Conclusion}

IT Providers can enable the Telecom Tower Infrastructure Industry with "Smart" \& "Sustainable" solutions that can help the companies improve on all the essential ROI Drivers - Revenue, OPEX, CAPEX and Partner management and at the same time enable them to be front runners in fulfilling Corporate Social Responsibility for a Greener environment.

The optimization of costs, as initiated through the effective sharing of infrastructure, needs to be further supported by Energy reduction including transition to renewable energy sources. Given the current scenario of the industry, large cash-rich players are more suited to direct the industry, by investing in R\&D in collaboration with IT Providers.

With the major push in terms of coverage likely to be over in the near future, the industry is readying itself to enter the next phase of development where capacity augmentation would be primarily going to be driven by the market. The three main pillars - Consolidation, Focus on Tenancies and Energy Management - will act as key thrust areas for this industry.

Tower Infrastructure Cos can contribute significantly towards "Greener" Environment by reducing their Carbon Footprint through proper implementation of "Smart" solutions. Green Telecom agreement should be adopted by all Telcos and Tower Infrastructure Cos to strengthen global initiatives under taken by Government of India. 
Availability of Technology and Resources are not the constraints, however ways and means needs to be developed for its promotion.

It is imperative for various stakeholders mentioned in the paper to work in a coherent approach. Leaders have to endeavor to become trusted advisers in their domain in meeting the common objectives.

With the recommendations as highlighted in the paper, it will enable Operators to take significant leap forward towards the implementation \& sustainability of advanced technologies leading to Greener \& Sustainable future. It is pertinent that telecom infrastructure proves cost effective and should be planned ahead of time with strong support from stakeholders / authorities.

\section{References}

ICRA. (February 2011). Indian Telecom Tower Industry: Consolidation Round the Corner. New Delhi, India.

Project with Maximum Business Impact: BHARTI INFRATEL's- Tower Operations and Asset Management Center. Retrieved from http://pcquest.ciol.com/content/contentimplementation2011/2011/211070103.asp

Telecom Operator News. Retrieved from http://tele.net.in

Telecom Regulatory Authority of India. ( $3^{\text {rd }}$ February 2011). Consultation on Green Telecommunications. New Delhi, India.

Telecom Regulatory Authority of India. ( $9^{\text {th }}$ November 2011). The Indian Telecom Services Performance Indicators. New Delhi, India.

Telecom Regulatory Authority of India. (12 ${ }^{\text {th }}$ April 2011). Recommendations on Approach towards Green Telecommunications. New Delhi, India. 